\title{
NUMERICAL RESEARCH OF THE MEASUREMENT ERROR OF TEMPERATURE THERMOCOUPLES WITH THE ISOLATED SEAL
}

Yuliana K. Atroshenko ${ }^{1}$, Alena A. Bychkova and Pavel A. Strizhak ${ }^{1}$

${ }^{1}$ National Research Tomsk Polytechnic University, 634050 Tomsk, Russia

\begin{abstract}
Mathematical models of heattransfer are developed for an assessment of measurement errors of temperature by thermocouples with an isolated and uninsulated seal. Dependences of necessary time of heating (for authentic measurement) for the thermocouples with an isolated seal manufactured of different materials are set. It is shown that for thermocouples with isolated seal minimum necessary duration of heating up slightly exceeds this index for thermocouples with an uninsulated seal.
\end{abstract}

\section{Introduction}

Measurements in management systems play an important role since on their basis all processes connected to correction of operation of technology equipment are executed. The key parameters characterizing technological processes on production, as a rule, are temperature and pressure. Therefore the accuracy of measurements of these parameters should pay special attention. Besides, the accuracy of measurements often influences not only quality of regulation and control of technological processes, but also safety of operation of the equipment [1,2]. Depending on the range of the taken temperatures and the required level of accuracy of measurements in systems of measurement and regulation thermocouples and resistance temperature detectors can be used. The condition of thermal contact, construction of the thermocouple, and also duration of execution of measurements have a great influence on the accuracy of contact measurements [3-6].

In the real operation models of thermocouples with an isolated and uninsulated seal are developed; results of numerical research, executed by means of these models are given.

\section{Physical model of heat transfer}

The area of the solution of the task represents the non-uniform system "a thermocouple seal - a ceramic cap - powder - a protective cover - air" which geometrical representation is given in fig. 1 .

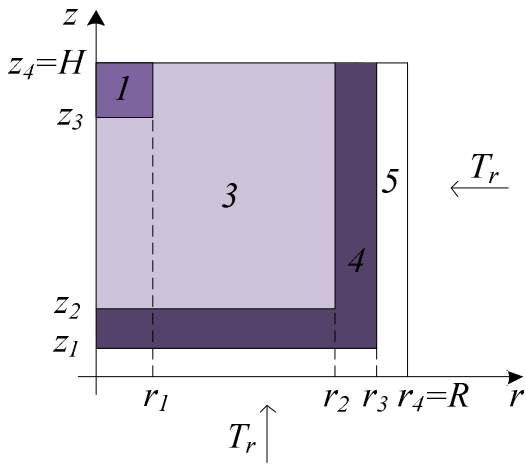

a)

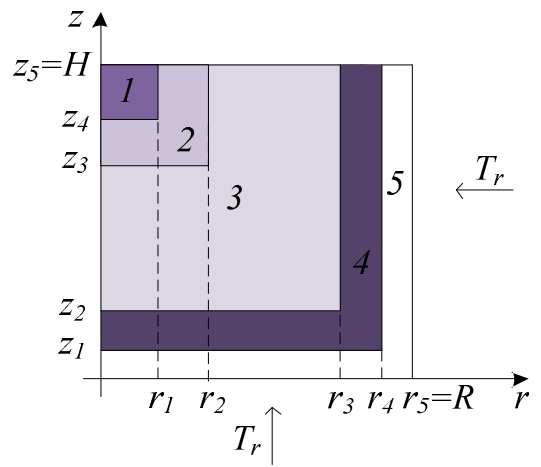

b)

Figure 1. Area of the solution of the task: 1 - thermocouple junction, 2 - insulating cap; 3 - poweder Al2O3; 4 metal cover; 5 - air

This is an Open Access article distributed under the terms of the Creative Commons Attribution License 4.0, which permits unrestricted use, distribution, and reproduction in any medium, provided the original work is properly cited. 


\section{MATEC Web of Conferences}

In case of the solution of the task it is accepted that heatphysical characteristics of elements of area of the decision don't depend on temperature.

The decision of the task of heat conduction was passed taking into account that the initial temperature of system corresponds to reference conditions and makes $20^{\circ} \mathrm{C}$, and heating up produced from the surface separated from the thermocouple by air gap. A condition of the end of heating up achievement serves as a thermocouple junction of temperature which will differ from the taken temperature on the value which isn't exceeding admissible a deviation for this type of the thermocouple.

For the thermocouple of the $\mathrm{S}$ type blundered in the researched range of temperatures it is constant and makes $1,5{ }^{\circ} \mathrm{C}$, for the thermocouple of $\mathrm{L}$ type in the range of temperatures $-40 \ldots 300{ }^{\circ} \mathrm{C}$ blundered make $\pm 2,5{ }^{\circ} \mathrm{C}$, in case of measurement of temperatures in the range $300 \ldots 800{ }^{\circ} \mathrm{C}$ the permissible deviation is defined by dependence $\pm 0,0075 \mathrm{t}^{\circ} \mathrm{C}$. The thermocouple of $\mathrm{K}$ type in the range $-40 \ldots$ has $375{ }^{\circ} \mathrm{C}$ blundered $\pm 1,5^{\circ} \mathrm{C}$ and $\pm 0,004 \mathrm{t}$ in the range of temperatures $375 \ldots 1000{ }^{\circ} \mathrm{C}$ [8].

The sensitive element of the typical thermocouple has the cylindrical form with a diameter of 5 $\mathrm{mm}$, height of the modelled section of the thermocouple is accepted $5 \mathrm{~mm}$ from the lower bound.

\section{Mathematical model}

The two-dimensional model of heattransfer (fig. 1) is described by the differential equations given in table 1.

Table 1. Mathematical model

\begin{tabular}{|c|c|c|}
\hline \multirow{2}{*}{ № i/s } & For area (fig. 1, a) & For area (fig. 1, b) \\
\hline & \multicolumn{2}{|c|}{ Heat conduction equations } \\
\hline (1) & $\begin{array}{c}c_{1} \rho_{1} \frac{\partial t_{1}}{\partial t}=\lambda_{1}\left(\frac{\partial^{2} t_{1}}{\partial r^{2}}+\frac{1}{r} \frac{\partial t_{1}}{\partial r}+\frac{\partial^{2} t_{1}}{\partial z^{2}}\right) \\
t>0,0<r<r_{1}, z_{3}<z<H\end{array}$ & $\begin{array}{c}c_{1} \rho_{1} \frac{\partial t_{1}}{\partial t}=\lambda_{1}\left(\frac{\partial^{2} t_{1}}{\partial r^{2}}+\frac{1}{r} \frac{\partial t_{1}}{\partial r}+\frac{\partial^{2} t_{1}}{\partial z^{2}}\right) \\
t>0,0<r<r_{1}, z_{4}<z<H\end{array}$ \\
\hline (2) & $\begin{array}{c}c_{3} \rho_{3} \frac{\partial t_{3}}{\partial t}=\lambda_{3}\left(\frac{\partial^{2} t_{2}}{\partial r^{2}}+\frac{1}{r} \frac{\partial t_{3}}{\partial r}+\frac{\partial^{2} t_{3}}{\partial z^{2}}\right) \\
t>0,0<r<r_{2}, z_{2}<z<z_{3} \\
t>0, r_{1}<r<r_{2}, z_{3}<z<H\end{array}$ & $\begin{array}{c}c_{2} \rho_{2} \frac{\partial t_{2}}{\partial t}=\lambda_{2}\left(\frac{\partial^{2} t_{2}}{\partial r^{2}}+\frac{1}{r} \frac{\partial t_{2}}{\partial r}+\frac{\partial^{2} t_{2}}{\partial z^{2}}\right) \\
t>0,0<r<r_{2}, z_{3}<z<z_{4} \\
t>0, r_{1}<r<r_{2}, z_{4}<z<H\end{array}$ \\
\hline (3) & $\begin{array}{c}c_{4} \rho_{4} \frac{\partial t_{4}}{\partial t}=\lambda_{4}\left(\frac{\partial^{2} t_{4}}{\partial r^{2}}+\frac{1}{r} \frac{\partial t_{4}}{\partial r}+\frac{\partial^{2} t_{4}}{\partial z^{2}}\right), \\
t>0,0<r<r_{3}, z_{1}<z<z_{2} \\
t>0, r_{2}<r<r_{3}, z_{2}<z<H\end{array}$ & $\begin{array}{c}c_{3} \rho_{3} \frac{\partial t_{3}}{\partial t}=\lambda_{3}\left(\frac{\partial^{2} t_{3}}{\partial r^{2}}+\frac{1}{r} \frac{\partial t_{3}}{\partial r}+\frac{\partial^{2} t_{3}}{\partial z^{2}}\right) \\
t>0,0<r<r_{3}, z_{2}<z<z_{3} \\
t>0, r_{2}<r<r_{3}, z_{3}<z<H\end{array}$ \\
\hline (4) & $\begin{array}{c}c_{5} \rho_{5} \frac{\partial t_{5}}{\partial t}=\lambda_{5}\left(\frac{\partial^{2} t_{5}}{\partial r^{2}}+\frac{1}{r} \frac{\partial t_{5}}{\partial r}+\frac{\partial^{2} t_{5}}{\partial z^{2}}\right) \\
t>0,0<r<L, 0<z<z_{1} \\
t>0, r_{3}<r<R, z_{1}<z<H\end{array}$ & $\begin{array}{c}c_{4} \rho_{4} \frac{\partial t_{4}}{\partial t}=\lambda_{4}\left(\frac{\partial^{2} t_{4}}{\partial r^{2}}+\frac{1}{r} \frac{\partial t_{4}}{\partial r}+\frac{\partial^{2} t_{4}}{\partial z^{2}}\right) \\
t>0,0<r<r_{4}, z_{1}<z<z_{2} \\
t>0, r_{3}<r<r_{4}, z_{2}<z<H\end{array}$ \\
\hline (5) & & $\begin{array}{c}c_{5} \rho_{5} \frac{\partial t_{5}}{\partial t}=\lambda_{5}\left(\frac{\partial^{2} t_{5}}{\partial r^{2}}+\frac{1}{r} \frac{\partial t_{5}}{\partial r}+\frac{\partial^{2} t_{5}}{\partial z^{2}}\right) \\
t>0,0<r<L, 0<z<z_{1} \\
t>0, r_{4}<r<R, z_{1}<z<H\end{array}$ \\
\hline & BC & tions \\
\hline
\end{tabular}




\begin{tabular}{|c|c|c|}
\hline (6) & $\begin{array}{c}T_{i}\left(r_{i}, z\right)=T_{i+2}\left(r_{i+2}, z\right) ; \\
-\left.\lambda_{i} \frac{\partial T_{i}}{\partial r}\right|_{r=r_{i}}=-\left.\lambda_{i+2} \frac{\partial T_{i+2}}{\partial r}\right|_{r=r_{i+2}, i=1}\end{array}$ & $\begin{array}{c}T_{i}\left(r_{i}, z\right)=T_{i+1}\left(r_{i+1}, z\right) ; \\
-\left.\lambda_{i} \frac{\partial T_{i}}{\partial r}\right|_{r=r_{i}}=-\left.\lambda_{i+1} \frac{\partial T_{i+1}}{\partial r}\right|_{r=r_{i+1}, i=1 \ldots 5}\end{array}$ \\
\hline (7) & $\begin{array}{c}T_{i}\left(r_{i}, z\right)=T_{i+1}\left(r_{i+1}, z\right) ; \\
-\left.\lambda_{i} \frac{\partial T_{i}}{\partial r}\right|_{r=r_{i}}=-\left.\lambda_{i+1} \frac{\partial T_{i+1}}{\partial r}\right|_{r=r_{i+1}, i=2 \ldots 5}\end{array}$ & $r=0, \frac{\partial T}{\partial r}=0$ \\
\hline (8) & $r=0, \frac{\partial T}{\partial r}=0$ & $z=0 ; T=T_{r}$ \\
\hline (9) & $z=0 ; T=T_{r}$ & $z=H ; \frac{\partial T}{\partial r}=0$ \\
\hline (10) & $z=H ; \frac{\partial T}{\partial r}=0$ &
\end{tabular}

Here $\mathrm{r}$ - radial coordinate, $\mathrm{m} ; \mathrm{z}$ - axial coordinate, $\mathrm{m}$; $\mathrm{c}$ - specific heat capacity, $\mathrm{J} /\left(\mathrm{kg} \cdot{ }^{\circ} \mathrm{C}\right) ; \rho-$ density, $\mathrm{kg} / \mathrm{m}^{3} ; \lambda$ - coefficient of heat conduction, $\mathrm{W} /\left(\mathrm{m} \cdot{ }^{\circ} \mathrm{C}\right)$; indexes: 1 thermocouple junction, 2 - protective cap; 3 - powder of an aluminum oxide, 4 -protective cover, 5 - air.

Initial conditions difine the temperature distribution in the thermocouple's sensitive element in an initial time point:

$t=0 ; t=t_{0}, 0<r<R$,

$t=0 ; t=t_{0}, 0<z<H$,

where $t_{0}=20^{\circ} \mathrm{C}$ - temperature corresponding to reference conditions.

Boundary conditions of heat transfer problem solution domain are defined as follows.

Boundary conditions of the first kind are set on $r=R$ boundary: $r=R, t=t_{\mathrm{p}}$, where $t_{r}-$ temperature of a heating element.

\section{Solution Procedures}

The area of the solution of the task (fig. 1) is broken into the uniform grid consisting of 240 nodes. The slot pitch on radial and axial coordinates is equal $2,5 \cdot 10^{-2} \mathrm{~mm}$. The step on a temporal grid changed in the range from $10^{-4}$ to $10^{-2}$ with for reduction of volume of computation and increase of accuracy of the decision.

Systems of equations (1)-(5) with the appropriate initial and boundary conditions decided using a method of finite differences. The solution of the difference analogs of the differential equations representing the linear algebraic equations was carried out by a local and onedimensional method. The pro-race method on the basis of the implicit four-point diagram [9] was applied to the decision of system of the difference equations.

\section{Results and discussion}

Thermal and physical characteristics of elements of one-dimensional and two-dimensional heat transfer problem solution domain are presented in Table 2.

Table 2. Thermal and physical characteristics of materials [10-11]

\begin{tabular}{|l|l|l|l|l|}
\hline № & Material name & Heat conduction & Specific heat & Density \\
\hline
\end{tabular}


MATEC Web of Conferences

\begin{tabular}{|c|l|c|c|c|}
\hline $\begin{array}{c}\text { materi } \\
\text { al }\end{array}$ & $\begin{array}{c}\text { coefficient } \lambda, \mathrm{W} / \\
(\mathrm{m} \cdot \mathrm{J})\end{array}$ & $\begin{array}{c}\text { capacity with, J } \\
(\mathrm{kg} \cdot \mathrm{J})\end{array}$ & $\rho, \mathrm{kg} / \mathrm{m}^{3}$ \\
\hline 1 & $\begin{array}{l}\text { Thermocouple junction } \\
(\text { type } L)\end{array}$ & 24.75 & 713 & 8920 \\
\hline 1 & $\begin{array}{l}\text { Thermocouple junction } \\
(\text { type } K \text { ) }\end{array}$ & 33.1 & 768 & 8825 \\
\hline 1 & $\begin{array}{l}\text { Thermocouple junction } \\
\text { (type } S \text { ) }\end{array}$ & 50.4 & 139 & 20710 \\
\hline 2 & Ceramic case & 16 & 1050 & 3800 \\
\hline 3 & Powder $\mathrm{Al}_{2} \mathrm{O}_{3}$ & 6.57 & 850 & 1520 \\
\hline 4 & $\begin{array}{l}\text { Protective cover } \\
\text { Steel }\end{array}$ & 15 & 462 & 7900 \\
\hline 5 & Air & 0.026 & 1190 & 1.161 \\
\hline
\end{tabular}

Dependences of duration of heating up of thermocouples on the taken temperature with an isolated seal for $\mathrm{K}$ and $\mathrm{L}$ thermocouples taking into account existence of air gap of $1 \mathrm{~mm}$ are given in fig. 2 .

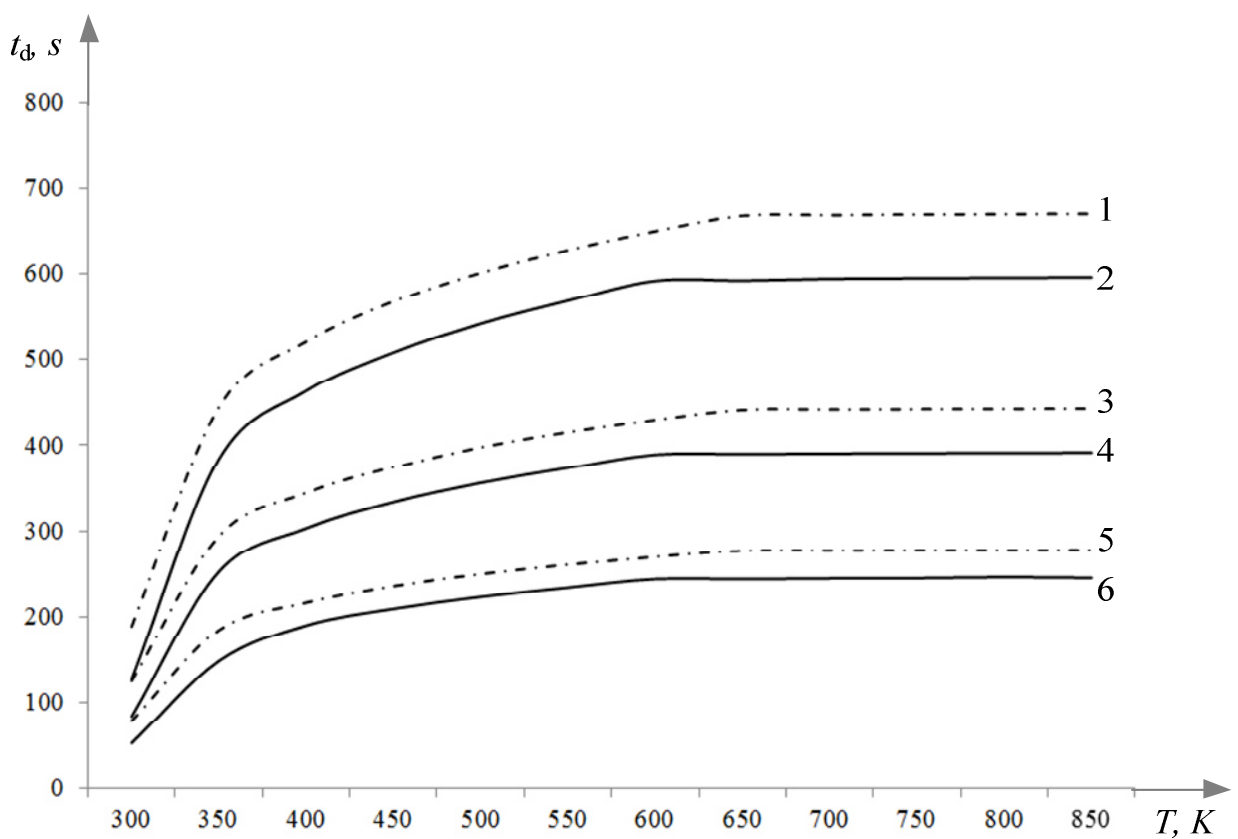

Figure 1. Dependence of duration of heating up of the thermocouple on the taken temperature for different values of air gap for the thermocouple of $\mathrm{K}$ type and L type: $\mathrm{L}$ type: $2-3 \mathrm{~mm} ; 4-2 \mathrm{~mm} ; 6-1 \mathrm{~mm}$; K type: $1-3 \mathrm{~mm}$; $3-2 \mathrm{~mm} ; 5-1 \mathrm{~mm}$

The analysis of fig. 2 shows that with increase in temperature heating up duration nonlinearly increases and for the thermocouple of $\mathrm{K}$ type slightly exceeds heating up time for the thermocouple of $\mathrm{L}$ type, in case of temperature measurement more than $600 \mathrm{~K}$ heating up duration practical doesn't change. Besides, the size of air gap between the thermocouple and the heater increases heating time for $1 \mathrm{~mm}$ on average by 1,5 times, and by $2 \mathrm{~mm}-$ by 2,4 times.

Values of duration of heating up of thermocouples with an isolated and uninsulated seal in the conditions of existence of air gap $1 \mathrm{~mm}$ thick are given in table 3 . 
Table 3. Duration of heating up of thermocouples with different construction

\begin{tabular}{|c|c|c|c|c|c|c|}
\hline \multirow{2}{*}{$\begin{array}{c}\text { The token } \\
\text { temperature }\end{array}$} & \multicolumn{2}{|c|}{ Type L } & \multicolumn{2}{c|}{ Type K } & \multicolumn{2}{c|}{ Type S } \\
\cline { 2 - 7 } & $\begin{array}{c}\text { Uninsulated } \\
\text { seal }\end{array}$ & Isolated seal & $\begin{array}{c}\text { Uninsulated } \\
\text { seal }\end{array}$ & Isolated seal & $\begin{array}{c}\text { Uninsulated } \\
\text { seal }\end{array}$ & Isolated seal \\
\hline 300 & 49,976 & 52,437 & 74,801 & 78,411 & 72,379 & 75,336 \\
\hline 350 & 150,959 & 158,030 & 176,060 & 184,360 & 170,492 & 177,230 \\
\hline 400 & 181,285 & 189,740 & 206,470 & 216,180 & 199,956 & 207,820 \\
\hline 450 & 199,748 & 209,045 & 224,990 & 235,550 & 217,894 & 226,450 \\
\hline 500 & 213,061 & 222,996 & 238,340 & 249,510 & 230,828 & 239,880 \\
\hline 550 & 223,479 & 233,859 & 248,780 & 260,440 & 240,951 & 250,400 \\
\hline 600 & 232,963 & 243,776 & 257,370 & 269,430 & 249,268 & 259,032 \\
\hline 650 & 233,377 & 243,678 & 264,400 & 276,780 & 256,327 & 266,360 \\
\hline 700 & 233,692 & 244,539 & 264,710 & 277,110 & 262,459 & 272,730 \\
\hline 750 & 233,939 & 244,797 & 264,960 & 277,370 & 267,880 & 278,360 \\
\hline 800 & 234,303 & 246,006 & 265,160 & 277,580 & 272,737 & 283,410 \\
\hline 850 & 234,506 & 245,178 & 265,320 & 277,750 & 277,138 & 287,980 \\
\hline
\end{tabular}

Follows from table 2 that for the thermocouples having an isolated seal, heating up duration slightly exceeds minimum necessary duration of heating up for thermocouples with an uninsulated seal: for 4,6\% - for $\mathrm{K}$ and $\mathrm{L}$ thermocouples and for 3,9\% for the thermocouple of $\mathrm{S}$ type.

\section{Conclusion}

The description of the two-dimensional mathematical models describing heattransfer in case of temperature measurement by thermocouples with an isolated and uninsulated seal is provided in operation. Based on the executed numerical research it is possible to draw the following conclusions:

1) Existence and thickness of air gap between the heater and the thermocouple has the considerable impact on value of necessary time of heating of a sensitive element for receiving authentic results of measurement;

2) Difference in minimum necessary duration of heating up of the thermocouple for execution of measurements with the minimum error are insignificant, therefore existence of an insulating ceramic cap has no essential impact on result of measurement.

\section{Acknowledgments}

This work was supported by the Russian Foundation for Basic Research, project 14-08-00057.

\section{References}

1. T. V. Borovkova, V.N. Yeliseyev, and I.I. Lopukhov, Phys. Part. Nuclei, 5, 3 (2008).

2. N. Zhu, K. Shan, S. Wang, and Y. Sun, Energ. Buildings, 67 (2013).

3. L. Tsikonis, J. Albrektsson, J.Van herle, and D. Favrat, J. Power Sources, 245 (2014).

4. G.V. Kuznetsov and K.M. Mukhammadeev, J. Engineering Thermophysics, 19, 1 (2010).

5. Y. K. Atroshenko, I.P. Ozerova, P. A. Strizhak, Adv. Mater. Res., 1040 (2014).

6. Y. K. Atroshenko, P.A. Strizhak, O.S. Yashutina, EPJ Web of Conferences 82, 01061 (2015).

7. G. Beges, M. Rudman, J. Drnovsek, Int. J. Thermophys., 32 (2011).

8. IEC 60584-2. International standard. Thermocouples. Part 2: Tolerances, 1989.

9. A. A. Samarskii, The Theory of Difference Schemes, Marcel Dekker, Inc., USA, 2001.

10. N.B. Vargaftik, Reference Book on Thermophysical Properties of Gases and Liquids, Stars, Moscow [in Russian], 2006.

11. R. Hultgren Selected Values of the Thermodynamic Properties of Binary Alloys, USA, American Society for Metals, 1973. 